\title{
Mothers' Awareness And Experiences Of Having A Thalassemic Child: A Qualitative Approach
}

\author{
Kamran Ishfaq \\ Department of Social Welfare \\ The Children's Hospital \& the Institute of Child Health Multan \\ Mehreen Hashmi \\ Department of Social Work \\ Institute of Social Sciences, BahauddinZakariya University Multan \\ Salman Bin Naeem \\ Library Department \\ The Children's Hospital and Institute of Child Health, Multan, Pakistan
}

\begin{abstract}
The purpose of this study is to understand the mothers' level of awareness regarding thalassemia and their experiences of having a thalassemic child. A total of $(\mathrm{N}=64)$ mothers are chosen as participants. Focus Group Discussion (FGD) is carried out. Majority of the children's parents is cousins but they are not screened for thalassemia before marriage and despite of the birth of thalassemic child, they are unaware about pre-natal diagnosis. The study highlights the need of implementing effective public educational programs and to make pre-marital screening compulsory for general public to reduce the prevalence rate of the disease.
\end{abstract}

Keywords: Mothers, Awareness, Experiences, Thalassemia Child

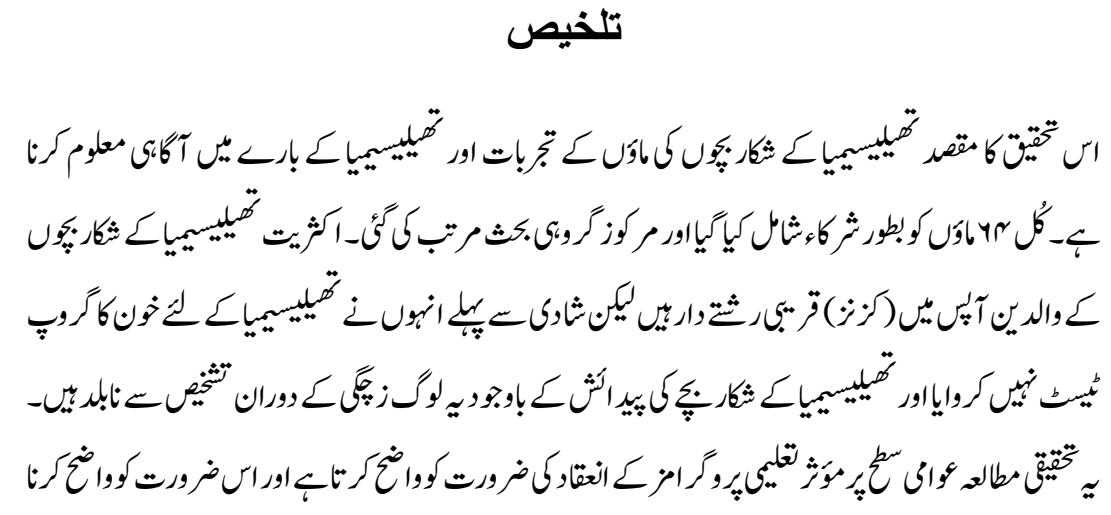




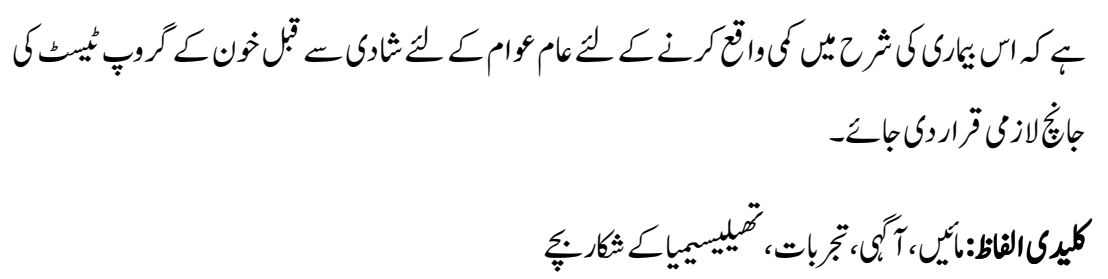

\section{Introduction}

Thalassemia major is an inherited haematological disorder leading to anaemia in affected children. It is an autosomal recessive disease in which chromosome 11 is involved. It affects synthesis of the B globin chain of haemoglobin which is either decreased or absent leading to early turnover of Red Blood Cell (RBC). When one of the beta globin chain gene is normal and other abnormal, it is thalassemia minor. If both the genes are involved and disorder presents late in life (older children and adults), it is called as thalassemia intermedia. If both the genes are involved and disorder is manifested early in life (infants) it is called as thalassemia major which is a more aggressive disease. Abnormal shaped RBCs are rapidly destroyed by the reticuloendothelial system particularly spleen leading to microcytic hypochromic anaemia and iron overload (Porecha, Udani, Mehta, and Gami, 2010).

Thalassemia is a serious health problem in Pakistan; approximately 5 to 6 million children are suffering from this disease or carrying its symptoms (Khattak, 2006), over 5000 thalassemia homozygotes are born every year (Ishaq, Abid, Koktab, Akhtar and Mehmood, 2012), and 6\% people are carrying the genes of Thalassemia due to abnormal production of haemoglobin (Saif-ur-Rehman, 2002). These numbers are alarmingly growing due to lack of awareness, insufficient educational campaigns, as reported by Saif-ur-Rehman (2002) that most of the mothers with thalassemia traits never come to know that they are carrying the genes as thalassemic carriers are healthy and they are the source of spreading the disease. Disease can only be diagnosed through blood investigation but people fear to get the carrier test due to discrimination and adverse implications in marriage prospects, unawareness to disease is another reason for not getting screened. Thalassemia poses tremendous physical problem in the affected children, as they are dependent on regular blood transfusions (Prasomsuk \& Jetsrisuparp, 2007) and need to be treated throughout their lives (Sattari, et al, 2012). As a result, the disease causes some other medical problems to the patients i.e patients will have pale colour, thalassemicfacies, exhaust and cannot do hard 
work (Anie \& Massaglia, 2001; Goldbeck et al., 2000; Louthrenoo et al., 2000). Moreover, the disease causes effects to patients' mental, feeling of helplessness, un-acceptance, loss and grief (Aydin et al., 1997; Nash, 1990; Politis, 1998; Tsiantis et al., 1986). Similarly, thalassemia is a major disease and its complications carry an important psychological, social and financial impact on patients' families, causing emotional burden, hopelessness, disease management, financial constraint and complexity with social integration. (Mazzone, Battaglia, Andreozzi, and Romeo, 2009; Liem, Gilgour, Pelligra, Mason \& Thompson, 2011).

The limited numbers of studies have been carried out in Pakistan. These studies have reported the impact of thalassemia major on patients and their families, is alarming. Thalassemia not only affects the child's health but also affects the socio-economic condition of the families and leaves devastating psychological and financial burden on patients' families (Saif-ur-Rehman, 2002; Zaman, 2006; $\&$ Arif, 2008). Many other studies carried out around the world have reported poverty, illiteracy, endogamous marriages, lack of anti thalassemic program and lack of awareness to disease are among the major barriers towards the better treatment of the thalassemic children and prevalence of the disease (Nikam, Dama, \& Patil 2012; Arif, Fiaz \& Hamid, 2008; Zaman, \& Salahuddin, 2006; Sharghi, Karbakhsh, Nabaei, Meysamie \& Farrokhi, 2006). There is little understanding of parent's awareness and knowledge regarding the disease and its impact on patients and families. In addition, thalassemia-related needs for prevention have hardly been studied in our population. According to Wong, George and Tan (2011) an in-depth understanding of attitudes, awareness, perceptions, and screening reservations regarding thalassemia is essential to launch an effective educational campaign to overcome the disease prevalence. Therefore, this study was carried out with an objective to describe the belief of mothers about their child disease, awareness and knowledge about thalassemia, impact of thalassemia on patients and their families, preventive measures and their future concerns regarding thalassemia. 
Table: 1

Focus Group Questions and Domains of Discussion

\begin{tabular}{|c|c|}
\hline Domain & Questions \\
\hline $\begin{array}{l}\text { Belief about child } \\
\text { disease. }\end{array}$ & $\begin{array}{l}\text { What is your belief, as a mother, to have a child with } \\
\text { thalassemia? }\end{array}$ \\
\hline $\begin{array}{l}\text { Awareness and } \\
\text { knowledge about } \\
\text { thalassemia. }\end{array}$ & $\begin{array}{l}\text { What do you know, as a mother of affected child, about } \\
\text { thalassemia? } \\
\text { What do you know, as a mother, about your child } \\
\text { disease? } \\
\text { What do you know, as a mother, about the choices of } \\
\text { treatment for your child disease? }\end{array}$ \\
\hline $\begin{array}{l}\text { Thalassemia } \\
\text { impact on child } \\
\text { and parents }\end{array}$ & How has thalassemia affected your child and family? \\
\hline $\begin{array}{l}\text { Prevention and } \\
\text { future concerns }\end{array}$ & $\begin{array}{l}\text { What can be the possible preventive mechanism to stop } \\
\text { thalassemia? } \\
\text { What is your future concerns regarding thalassemia? }\end{array}$ \\
\hline
\end{tabular}

\section{Material and Methods}

We relied on purposive sampling; participants were included in this study who met the established criteria. Criteria include (1) parent of a child affected with thalassemia, who requires blood transfusion support (2) child who is registered in one of these centers (i) The Children's Hospital \& the Institute of Child Health Multan, (ii) Fatimid Foundation, (iii) MinhajUl Quran, (iv) Amina Blood Foundation. A total of $(\mathrm{N}=64)$ sample was drawn and participants were divided equally $(n=16)$ from 04 blood transfusion centers. We conducted 08 focus group discussions (FGDs) divided equally into 08 groups comprising $(n=2)$ participants from each blood transfusion centers. Mothers rather than their affected children were chosen as participants because we trust that mothers can demonstrate the impact of thalassemia on both their children and the family in a better way. A semi-structure focus group moderator's guide corresponding to the research questions was developed. To gain in-depth understanding, we divided questions in four major domains which were (i) Belief about child disease, (ii) awareness and knowledge about thalassemia, (iii) thalassemia impact on child and family, and (iv) prevention and future concerns. Participants voluntarily participated in FGDs, which were carried out from August, 2013 to October, 2013. Before conducting 
FGDs, a written questionnaire was completed by participants in order to gather information about their demographic backgrounds (Table. III). Majority (54.6\%) of the participants were illiterate, therefore, keeping in view the convenient for participants, FGDs were conducted in Urdu and other regional languages such as Saraiki and Punjabi. Written informed consent was obtained from all participants. The moderators have read a brief excerpt about thalassemia and showed an illustration about the inheritance patterns at each session before the proceeding of discussion about belief and perceptions of thalassemia. The excerpt that was read out to all the focus groups state 'Thalassemia is a disease with low numbers of red blood cells or shortage of blood. Thalassemia is an inherited blood disorder which is passed from parents to their children. The two main types of thalassemia are called alpha and beta thalassemia. When two individuals with the same thalassemia trait have children, for each pregnancy there is a $25 \%$ chance of having a child with a severe form of the disorder. There is a 50\% (2 in 4) chance that the child will inherit one normal and one mutant gene (a carrier of the disease) and have a trait like the parents; and a 25\% (1 in 4) chance that the child will be completely free of the disease (normal). For each pregnancy, there is a $25 \%$ chance of having an unaffected child'. Throughout the FGDs, the term "thalassemia" refers to the homozygous form of the disease or thalassemia major. The term "thalassemia carrier" refers to the carrier state for thalassemia major. The FGDs were continued until data saturation was reached or no new information was uncovered. Coding and categorizing was carried out using QSR NVivo-7. Transcripts were thematically coded according to the research themes that emerged from the discussions, and the themes were further sorted into subthemes. This study was approved by the Medical Ethics Committees of each participated Thalassemic Centers.

Focus group discussions were recorded in two ways (i) taking notes and (ii) tape recording. Notes were consisted primarily of key phrases; lists of major points made by the participants were noted down. Key terms or words, shown in quotation mark capture the participant's own language. The main purpose of the written notes was to collect high quality data. Moderator made short notes quickly without intervening ongoing discussion. In addition to increase the accuracy of data collection, tape recorder was also used which permitted the moderator to remain more attentive to the participant. The researchers themselves acted as moderators. The comfortable and neutral places were selected for participants in group discussion. The chairs were arranged in ' $U$ ' shape pattern with equal distance around the table. Before starting the each FGDs, a purposeful small talk 
was conducted in order to create an excited, comfortable and conducive environment. The effort was made to control the discussion group with proper techniques. Aggressive and dominants participants were controlled and introverted participants were encouraged to participate in the discussion. After discussion, tape recorder was turned off and a word of thanks was given to the participants. Then it was again asked if something is missing in the discussion to be told.

\section{Analysis of Focus Group Discussions}

For the data analysis of FGDs, content analysis technique was used, which is defined as "A research technique for the systematic, objective, and quantitative description of overt content of communications" (Berelson, 1974). This technique is used to estimate the occurrence of certain concept or views within texts or sets of texts. Three moderators were involved to code the data into classification and results of coding were compared and discussed.

Table: 2

Codes and Sub codes from Focus Group Discussions

\begin{tabular}{|c|c|}
\hline Domains & Final Codes and Subcodes \\
\hline Belief about child disease & $\begin{array}{c}\text { Belief of Disease (BD) } \\
-\quad \text { BD- Religious Faith } \\
-\quad \text { BD- Cousin Marriage } \\
-\quad \text { BD- Childhood Illness } \\
-\quad \text { BD- Mother responsible }\end{array}$ \\
\hline Awareness and knowledge about thalassemia & 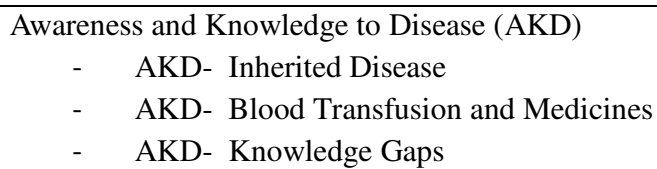 \\
\hline Thalassemia impact on child and parents & $\begin{array}{cl}\text { Child Impact (CI) } \\
-\quad \text { CI- Chronic Ailment } \\
-\quad \text { CI- Disease Treatment } \\
-\quad \text { CI- Social and Emotional } \\
\text { Parental Impact (PI) } \\
-\quad \text { PI- Financial } \\
-\quad \text { PI- Emotional and Social } \\
-\quad \text { PI- Weakness in Parental relationship }\end{array}$ \\
\hline Prevention and future concerns & $\begin{aligned} \text { Preventive Mechanism (PM) } \\
-\quad \text { PM- Pre-marital Screening } \\
-\quad \text { PM -Educational Program } \\
\text { Future Concerns (FC) } \\
-\quad \text { FC- Hope for Cure } \\
-\quad \text { FC- Availability of Blood }\end{aligned}$ \\
\hline
\end{tabular}


Table: 3

Demographic Characteristics of Respondents $(\mathrm{N}=64)$

\begin{tabular}{|c|c|c|}
\hline Demographic variables & Total sample N & $\%$ \\
\hline \multicolumn{3}{|l|}{ Gender } \\
\hline Female & 64 & 100 \\
\hline \multicolumn{3}{|l|}{ Marital status } \\
\hline Married & 60 & 93.7 \\
\hline Divorced & 2 & 3.1 \\
\hline Widow & 2 & 3.1 \\
\hline \multicolumn{3}{|l|}{ Type of Marriage } \\
\hline Cousin marriage & 52 & 81.2 \\
\hline Marriage with relative & 9 & 14.0 \\
\hline Out of family & 3 & 4.6 \\
\hline \multicolumn{3}{|l|}{ Age } \\
\hline$<20$ & 4 & 6.2 \\
\hline $21-30$ & 46 & 71.8 \\
\hline $31-40$ & 8 & 12.5 \\
\hline $41-50$ & 5 & 7.8 \\
\hline$>50$ & 1 & 1.5 \\
\hline \multicolumn{3}{|c|}{ Highest Education Attainment } \\
\hline Illiterate & 35 & 54.6 \\
\hline Primary School & 15 & 23.4 \\
\hline Secondary School & 8 & 12.5 \\
\hline Matriculation & 2 & 3.1 \\
\hline Graduation & 4 & 6.2 \\
\hline \multicolumn{3}{|l|}{ Occupation } \\
\hline Unemployed & 18 & 28.1 \\
\hline Business & 9 & 14 \\
\hline Private Employee & 10 & 15.6 \\
\hline Government Employee & 13 & 20.3 \\
\hline Laborer & 6 & 9.3 \\
\hline Other & 8 & 12.5 \\
\hline \multicolumn{3}{|l|}{ Monthly income in PKR } \\
\hline$<5000$ & 13 & 20.3 \\
\hline $5000-7500$ & 18 & 28.1 \\
\hline $7501-10000$ & 16 & 25 \\
\hline
\end{tabular}




\begin{tabular}{|l|c|c|}
\hline $10001-12500$ & 6 & 9.3 \\
\hline$>12500$ & 11 & 17.1 \\
\hline \multicolumn{3}{|l|}{} \\
\hline Residential Area & 22 & 34.3 \\
\hline Urban & 42 & 65.6 \\
\hline
\end{tabular}

\section{Theme 1: Belief about Child's Disease}

Data elements related to this theme were identified by questioning the mothers to discuss their belief to have a child with thalassemia and reason of child disease. Mothers demonstrated various beliefs about their child disease but religious faith was the most frequently applied code to our transcripts and emerged as a dominant theme. Mothers expressed that it is the will of GOD and a trial from GOD to their faith that how firm they are in religious teachings and how do we thank to the blessings of Allah even in times of adversity. One of the mothers said:

'Humans do not have power to do anything without the will of Allah, it's all planned and written that what is going to be happen; we just act accordingly so do the disease of my child was written. Everything in this world is fragile and everything has to come to its eternal end, the real world is hereafter'.

In our transcript, cousin marriage was emerged as an important secondary theme. Mothers were blaming and cursing their marriages with their cousins, to them this was a reason for their child disease.

'I really did not know before that a cousin marriage gives birth to so many diseases until I found my child's disease. I wish I could knew it before, I could have option then, but now I got no option except to take care of my child and get him treated rest of his whole life'.

Mothers also discussed their belief about child disease in these other areas, 'childhood illness' was another reason for thalassemia that due to constant illness in early months became a reason for a child disease, mothers were also disappointed from the behaviour of society and they discussed that society considered them responsible for child disease because it's a male dominant society and women are always considered responsible for every bad.

'When she was born, she used to remain sick most of the time and we used to get her treated from hakeem available in village but after few months she fell seriously ill for weeks with fever and when she got so weak then we were told by a 
neighbour that we should take her to city and get her treated from hospital and that was the first time when we were told by a doctor that amount of blood in her body was so less and we had to arrange blood for transfusion, that was a first time she received blood transfusion and up till now even right after 8 years we are compelled to get her a blood transfusion every month and sometimes after 20 days if she gets fever and ill meanwhile'.

\section{Theme II: Awareness and Knowledge about Thalassemia}

Across the group discussions, the vast majority of mothers were unable to give a correct definition of the disorder although some of the mothers correctly defined thalassemia as an inherited blood disorder. There were erroneous disbelief among mothers that thalassemia is a blood cancer. When probed further as to whether thalassemia is a communicable disease and can it be transmitted from one person to another, some mothers, majority from lower levels of educational achievement, were unsure.

'Blood transfusion is the treatment of my child because his body does not produce enough blood. Every month when my child is transfused, I do hope and believe that this is the last time and now after this blood transfusion my child will get alright and his body will start producing blood'

In our transcripts, lack of knowledge was emerged as another related theme. Mothers demonstrated lack of awareness and knowledge about thalassemia, its treatment and management. There was confusion between thalassemia major and carrier among mothers and majority of them were not able to tell the difference. There were wrong assumptions that all thalassemia major children are mentally retarded, physically abnormal, bedridden, and unable to carry out daily activities or attend school, some even believed that thalassemia carriers also exhibit similar symptoms and require blood transfusion. Knowledge about the genetics of thalassemia was also very poor. Many were unaware that both parents must be carriers in order to produce an affected child and that carrier parents have a ratio of 1:2:1 children who are normal, carrier, and thalassemia major. Across all FGDs, it was frequently misperceived that only one parent has to be a carrier to produce an affected child. Lack of Understanding to Medical Terminology emerged as a related theme. Mothers discussed that due to complex medical jargons and terminologies which are used by doctors, nurses and paramedical staff to explain something regarding child disease makes it difficult to understand about child disease. 
'I have been visiting to thalasemic centre for the blood transfusion of my daughter every month for the last seven years. Blood transfusion process takes 5 to 6 hours which includes blood test, cross match and blood transfusion. But I never acquire any knowledge about thalassemia from doctors or nurses. Because I am uneducated and I cannot understand their words'

'I want to know all about my child disease, what actually the disease is and what is its treatment, but no one ever told me about my child disease and its treatment in detail'

Mothers perceived thalassemia as, less serious and less dangerous and uncommon disease. They were not aware about the severity of the disease and complications associated with it. When asked that what is the treatment of their child's disease. Blood transfusion and medicines reply emerged as a major theme and mothers believed that blood transfusion and proper medication is the only treatment of their child.

'I do not know that thalassemia is connected with other diseases. I believe that blood transfusion is the real treatment of thalassemia'

Only $(n=4)$ mothers believed that bone marrow transplantation can save the lives of their children. Majority $(\mathrm{n}=60)$ of the mothers were not aware with the process of bone marrow transplantation. Mothers voiced that lack of information and awareness is one of the major causes of inadequate knowledge about thalassemia. Owing to the genetic complexity of the disease, mothers asked for educational material in layman's terms.

\section{Theme III: Impact of Thalassemia on Child and Family}

To know the impact of thalassemia on child and family, mothers were asked to give examples of specific factors that have affected the child and their parental lives. Separate codes for child and parental impact were used to identify the impact on specific areas including psychological, emotional, and financial state. Our Focus Group Discussions (FGDs) found a considerable impact of thalassemia on affected children and their parents. Child chronic ailment emerged as a major theme and it has more commonly impacted child. Mothers discussed that their children frequently catch fever and their growth is also delayed which is affecting child overall activities and most of time they cannot play with other children and if they play, they become fatigued. 
'I want my child to live a normal life like other children; I want him to go to school, to participate in routine activities, I want him to stay strong and face the world. I cannot see him suffering with this disease; I want him to fight with the disease,

In impact of thalassemia transcripts, disease treatment was emerged as an important secondary theme, mothers discussed the difficulties and miseries a child faces while getting blood transfusion and treatment every month which directly affects child's emotions and his school regularity.

'It's always hard for him to get pricked repeatedly for blood transfusion. He always forced me after every blood transfusion that now he will not come to hospital for blood transfusion, it's so painful. It's always hard for me to bring him to hospital for blood transfusion. He always comes to hospital weeping and asks me questions why do always take him to hospital; and he will not get the blood'.

Impacts of thalassemia on parental lives were significant. The impact of thalassemia on financial state was the most applied code to our transcripts and emerged as a dominant theme. Mothers expressed their financial expenditures on medicines, blood transfusion and treatment of their child, mothers voiced a financial constraint in order to provide a better treatment to their child including the financial expenditures, transportation, visits to doctors and hospital, blood tests, blood transfusion and purchase of medicines. Impact of thalassemia on emotional well-being was emerged as a related subtheme. Mothers expressed frustration, sadness and helplessness regarding the disease of their child. Another related theme that emerged from code was restricted social activities of the parents because of an affected child. Mothers discussed that due to the frequent illness of their child, most of time they are unable to participate in social activities such as family gathering and functions, related subtheme was financial constraint because they do spend most of the money on child treatment and they are unable to save enough money to go to family functions and to participate in social activities.

'People predict different things about my child's disease that makes me sad'.

In our transcripts, weakness in parental relationship emerged as a related subtheme. Mothers expressed that their lives would have been better and their relationship with their husbands would have been strong, if their child was normal. 
'I am not responsible for my child's disease, but my husband believes it's because of me. Now my life is not the same as it was before, I want my husband to talk to me about our child's disease and want him to go to doctors with me, to stay with me at the time of blood transfusion but it never happened and he put all the responsibility related to child's treatment and hospital visits on me'.

\section{Theme IV: Prevention and Future Concerns}

Data relevant to preventive mechanism were investigated using questions that asked mothers to discuss the possible preventive measures to stop thalassemia. Pre-marital screening was the most frequent applied code to our transcript related to preventive mechanism and emerged as a major theme. The majority of affected child mothers have never been tested for thalassemia, the reason was unawareness. Mothers discussed that pre-marital screening should be made mandatory for couples before marriage and it should be protected with law.

'In the context of our culture, where most of the marriages are performed between cousins and close relatives, pre-marital screening should be made compulsory for every couple. I do not want any other couple to become the victim of this disease and give birth to a thalassmic child'.

A related sub theme was pregnancy test for thalassemia, few mothers discussed that testing for thalassemia during pregnancy is helpful for mothers who already have a thalassemic child. Few mothers showed their concern that majority of mothers are not aware of this test. When probed further, whether test for deduction of thalassemia should be carried out during pregnancy, and in case test comes positive, will the pregnancy be terminated? There were mixed views regarding termination of pregnancy with thalassemia major if test indicates a thalassemic child during pregnancy. Women voiced that abortion is against Islam and have to see the stand of Islam on abortion, it must be clearly known whether this is against Islamic teaching or not.

Educational programs emerged as a second major theme relating to preventive mechanism, mothers did not know the incidence of thalassemia in Pakistan. Mothers made several suggestions, including dissemination of educational materials in the form of posters and pamphlets at public places such as shopping malls, markets and in marriage registries. Mothers also suggested that special educational sessions should be conducted for the parents of affected children, where parents should be educated about thalassemia, its preventive mechanism, 
and treatment of thalassemia and how to educate relatives and other family members in order to prevent them from thalassemic child. One of the mothers explained her concerns;

'I want to prevent my family members and relatives from this disease but I really do not know what exactly to tell relatives that what this disease is and what are the preventive measures to this disease'.

Mothers discussed their fears and future concerns about their child disease. In our transcript mothers' hope for a child cure emerged as a theme. Mothers were deeply concerned about the well-being of their children. They were desperately hoping to see their children healthy and normal. Mothers discussed their concern about treatment because currently, it has caused suffering for both parents and children. Mothers talked about their hopes for new treatments and the possibility of having healthy children in the future. Some mothers also showed their helplessness that children with this disease cannot live a long life. Nonavailability of blood emerged as another related sub theme. Mothers expressed their concern on the arrangement of blood for affected child every month and discussed that it is the most difficult job to arrange blood.

'How can we manage blood every month, neither anyone donates nor we can buy it. It is very hard to arrange blood every month. Earlier, hospital used to provide blood for transfusion and treatment was also free but now hospital does not provide it anymore and we do not have links to arrange blood'.

\section{Discussion}

To our knowledge, this is the first study in Pakistan which explored the mothers' belief regarding thalassemia, their awareness to disease, its impact on patients and families and future concerns of the 64 mothers of affected children. The primary themes that emerged from our analysis were (i) belief about child disease, (ii) awareness and knowledge about thalassemia, (iii) impact of thalassemia on child and families, (iv) prevention and future concerns. Our coding scheme led to the recognition of several important secondary themes. The findings of this study demonstrated that mothers' belief about their child disease was firm and they all have taken their child disease as a 'will of Allah'. We found their understanding to disease at a very low level; they explained that cousin marriage is the root cause of this disease but they were reluctant to have pre-marital screening and pre-natal diagnosis. The findings of this study correlate with other studies conducted by (Liem et.al, 2011; Prasomsuk \& Jetsrisuparp, 2007; Wong et.al, 2011; Zaman \& 
Salahuddin, 2006; \& Arif, Fiaz\& Hamid, 2008) that inadequate knowledge, lack of pre-marital screening practices; illiteracy and unawareness were the main reasons in prevalence of the disease. Findings showed that majority of the thalassemic children's parents were first cousins. Majority of mothers were illiterate. They were unfamiliar with any preventive measure during or before thalassemia. Zaman and Salahuddin (2006) concluded in their study that educated parents were taking preventive measures if a disease is presented in their families. But on the other hand, due to the high rate of illiteracy majority were not aware of the preventive measures. The study also highlights some fundamental misconceptions which include thalassemia is a blood cancer and blood transfusions is the only treatment for this disease. Such misconceptions clearly lead to unnecessary anxieties.

A disease was affecting parental financial state very badly, majority of the affected children's families were poor and unable to afford the costly treatment. Sattari et al., (2012) found a similar finding that disease causes financial impact on patient's families. The average cost for treatment of a thalassemic patient is around 10,000 PKR (100 USD) per month apart from blood arrangements, which is too high for a poor family (Khattak, 2006). Though, government is providing blood transfusion facilities; subsidize and free medicines in public teaching hospitals which are only limited to big cities. Similarly, many philanthropists and NGO's are working together for the treatment of the disease but this is not enough because the miseries of the poor patients is greater than the efforts made so far. If thalassemic children are not treated in time, they can die between the ages of 1-8 years (Saif, 2002). Therefore, proper and timely treatment is essential for the survival of affected children.

Thalassemia is a preventable disease and across all focus group discussions, the need for anti-thalassemic educational and awareness programs is highlighted. The only effective way to overcome the prevalence of thalassemia is to stop the birth of thalassemic children by making pre-marital screening compulsory for general public and counselling to the affected families (1992). Thalassemia has already been addressed successfully in many countries like Iran, Greece, Italy, and Cyprus by running educational campaigns; making people aware about the disease and highlighting its preventive measures to get rid of the disease. (Ishaq, Abid, Kokab, Akhtar \& Mehmood, 2012). Pre-natal diagnosis and carrier detection facility is available in Pakistan over a decade, but its use is still limited due to the lack of public knowledge and awareness. It is the need of time to realize the density of 
the disease and practical steps should be taken to reduce the prevalence of the disease. Therefore, it is important to make people aware about the disease, its complications and preventive measures. Anti-thalassemic public educational campaigns and programs should be arranged and carried out according to local cultural, educational status and religious beliefs (Wong, George and Tan, 2011). Public health message should aim to clarify all misconceptions and encourage carrier screening and pre-natal diagnosis that will eventually result in a reduction of thalassemia major births and prevalence of the disease. The limitation of this study was its nature of self-reported FGSs, though moderators tried to gain the possible real information from respondents. But all the information that have been attained from respondent's discussion was self-reported. Thus self-report bias towards socially desirable results might exist. Other limitation was few respondents' inability to participate actively in a discussion because majority of the respondents were illiterate. Though FGDs carried out in local languages but still dominancy of few respondents were observed but moderators tried to overcome the dominancy of few respondents. The important implications that have emerged from the findings of this study are (i) pre-marital screening and prenatal diagnosis, (ii) provision of blood transfusions facilities, and (iii) public education. Study demonstrated the current knowledge among affected child's mothers is inadequate. Therefore, knowledge regarding disease among mothers need to be improved. Health care providers need to enhance the mothers education regarding thalassemia major with respect to carrier, pre-marital screening and pre-natal diagnosis and reinforcement of medical education and improved efforts of clinical staff in providing practical knowledge regarding the disease of their child should significantly improve patient adherence to treatment. Moreover, cousin marriages are in vogue in Pakistani context, which tends to be a causative factor of the disease. Therefore, it is important implication if pre-marital screening may be made mandatory before marriages. There is need for further research to explore the related aspects of the disease, its consequences on a child and family lives, people awareness and knowledge to disease, and preventive measures in different context. In order to gain in-depth understanding of the issue and to fill the knowledge gaps which will help policy makers to address the issue in an effective way. Furthermore, research for generalization of findings using quantitative method is necessary. The researchers here recognized the role of library and information centers for providing information to the parents with thalassemic child i.e. awareness about cousin marriage, pre-marital screening, future complications, home care and normal health conditions. The health 
centres/hospitals library or mobile library can provide books, pamphlets, newsletters, video or audio tapes about thalassemia, flip-charts, and diagrams etc.

\section{Conclusions}

The finding of this study indicates significant impact of thalassemia on patients and their families in terms of financial state, emotional well-being and social activities. Majority of the children's parents was cousins but they have not been screened for thalassemia before marriage and despite of the birth of thalassemic child, they were unaware about pre-natal diagnosis. Mother's education level was very low about thalassemia. The finding of the present study also highlight the need of implementing effective public educational programs and to make premarital screening compulsory for general public to reduce the prevalence rate of the disease. Moreover, additional facilities for pre-marital screening and counselling should be made accessible and available to general public.

\section{References}

Anie, K.A., \& Massaglia, P. (2001). Psychological Therapies for Thalassemia, Cochrane Data Base Systematic Review, (3), CD002890. DOI: 10.1002/ 14651858.CD002890

Arif, F., Fayyaz, J., \& Hamid, A. (2008). Awareness among Parents of Children with Thalassemia Major, Journal of Pakistan Medical Association, vol.58:11, pp.621-623.

Aydin, B., Yaprak, I., Akarsu, D., Oktem, N., \& Ulgen, M. (1997). Psychosocial Aspects and Psychiatric Disorders in Children with Thalassemia Major, Acta Pediatrica Japan, vol.39, pp.354-357

Berelson, B. (1974). Content Analysis in Communication Research, Glencoe, III: Free Press.

Cappellini, N., Cohen, A., Eleftherion, A., Piga, A., \& Porter, J. (Eds.). (2000).Guidelines for the Clinical Management of Thalassemia, Nicosia, Cyprus: Thalassemia International Federation. 
Goldbeck, L., Baving, A., \& Kohne, E. (2000). Psychosocial Aspects of BetaThalassemia: Distress, Coping and Adherence. Klinische Padiatrie, vol.212:5, pp.254-259.

Ishaq, F., Abid, H., Kokab, F., Akhtar, A., \& Mehmood, S. (2012). Awareness among Parents of $B$-Thalassemia Major Patients, Regarding Pre-Natal Diagnosis and Pre-Marital Screening, Journal of College of Physicians and Surgeons Pakistan, vol.22:4, pp.218-221.

Khattak, I., Khattak, S.T., Khan, J. (2006). Heterozygous Beta Thalassemia in Parents of Children with Beta Thalassemia Major, Gomal Journal of Medical Sciences, vol.4:2, pp.52-56.

Liem, R.I., Gilgour, B., Pelligra, S.A., Mason, M. \& Thompson, A.A. (2011). The Impact of Thalassemia on Southeast Asian and Asian Indian Families in the United States: A Qualitative Study. Ethnicity \& Disease, vol.21:3, pp.361-369.

Louthrenoo, O., Sittipreechacharn, S.,fhanarat-tanakom, P., Sanguansermsri, T. (2000). Psychosocial Problems in Children with Thalassemia and their Siblings. Journal of Medical Association Thailand, vol:85, pp.881-885.

Mazzone, L., Battaglia, L., Andreozzi, F., Romeo, M.A., \& Mazzone, D. (2009). Emotional Impact in $\beta$-Thalassemia Major Children Following Cognitivebehavioural Family Therapy and Quality of Life of Caregiving Mothers. Clinical Practice and Epidemiology in Mental Health, vol.5:5, pp.1-6.

Nash, K.B. (1990). A Psychosocial Perspective. Growing up with Thalassemia, a Chronic Disorder, Annals of the New York Academy, vol.612, pp.442-450.

Nikam S. V., Dama S. B., Patil S.S. (2012). Literacy Status in Thalassemic Patients from Solapur District, Maharashtra, India: A Statistical Study, DAMA International, vol.1:1, pp.22-24.

Politis, C. (1998). The Psychosocial Impact of Chronic Illness. Annals of the New York Academy of Sciences, vol.850, pp.349-354. 
Porecha, M. M., Udani, D., Mehta, V., Gami, A. (2010). Splenectomy in Management of Thalassemia Major- A Boon for the Little Angel. Internet Journal of Surgery, vol.24:1. DOI: 10.5580/8f9

Prasomsuk, S., Jetsrisuparp, A., Ratanasiri, T., \& Ratanasiri, A. (2007). Lived Experiences of Mothers Caring for Children with Thalassemia Major in Thailand. Journal for Specialists in Pediatric Nursing, vol.12:1, pp.13-23.

Saif-ur-Rehman., Batool, S., \& Qadir, R. (2002). Socio-Economic Status of Impact Thalassemia Child on Families of Faisalabad District, Pakistan Journal of Applied Sciences, vol.2:2, pp.202-205.

Sattari, M., Sheykhi, D., Nikanfar, A., Pourfeizi, A.H., Nazari, M., Dolatkhah, R., \& Mashayekhi, M. (2012). The Financial and Social Impact of Thalassemia and its Treatment in Iran, Pharmaceutical Sciences, vol.18:3, pp.171-176.

Sharghi, A., Karbakhsh, M., Nabaei, B., Meysamie, A., \&Farrokhi, A.(2006). Depression in Mothers of Children with Thalassemia or Blood Malignancies: A Study from Iran. Clinical Practice and Epidemiology in Mental Health, vol.2:27, doi: 10.1 186/1745-0179-2.

Tsianitis, J., Dragonas, T., Richardson, C., Anastasopoulos, D., Masera, G., \& Spinetta, J. (1996). Psychosocial Problems and Adjustment of Children with B-thalassemia and their Families, European Child \& Adolescent Psychiatry, vol.5:4, pp.193-199.

Wong, L.P., George, E., Tan. (2011). Public Perceptions and Attitudes toward Thalassemia: Influencing Factors in a Multi-Racial Population. Bio Medical Central, Public Health, vol.11:193.

Zaman, Q., Salahuddin. (2006). Association between the Education and Thalassemia: A Statistical Study. Pakistan Journal of Statistics, vol.II:2, pp.103-110. 
Kamran Ishfaq is Social Welfare Officer at The Children's Hospital \& the Institute of Child Health, Multan. Pakistan.

Mehreen Hashmi is Lecturer in the Department of Social Work, Institute of Social Sciences, Bahauddin Zakariya University Multan, Pakistan.

Salman Bin Naeem is Librarian at The Children's Hospital \& Institute of Child Health, Multan. Pakistan. 